Natural and Applied Sciences International Journal (NASIJ)

https://doi.org/10.47264/idea.nasij/1.1.2

Vol. 1, No. 1, (January-December 2020), 11-20

https://www.ideapublishers.org/index.php/nasij

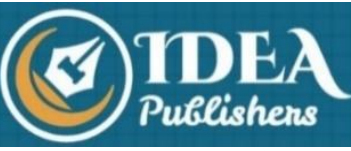

Research Article

\title{
Possible Seismo Ionospheric Anomalies before the 2016 Mw 7.6 Chile Earthquake from GPS TEC, GIM TEC and Swarm Satellites
}

\author{
Zahid U. Rahman* \\ Department of Computer Science, Comsats University, Islamabad, Pakistan. \\ * Corresponding Author Email: zahidktk369@gmail.com
}

\begin{abstract}
The recent advances in space based ionospheric measurements can help to investigate seismic precursors before earthquake with multi-parameter observations and more dedicated instrumentations. In this paper, seismo ionospheric anomalies before the December 25, 2016, Mw 7.6, Chile earthquake are investigated in Total Electron Content (TEC) and Global Ionosphere Map (GIM). The temporal TEC from GPS stations and GIM show enhancement during 5- 10 days (local daytime) before main shock. Similarly, spatial TEC confirms abnormal dense cloud at LT $=12 \mathrm{~h}-14 \mathrm{~h}$ on December 21,2016 , that lingers over the epicenter of Chile earthquake. On the other hand, the geomagnetic indices show Dst $<-50 \mathrm{nT}$ of low intensity variation. Similarly, Kp > 3 on December 21, 2016 within 5-10 days before the Mw 7.6. This study emphasizes that the ionosphere anomalies may not be the possible association of earthquakes induced variation but it is due to the active storm conditions (Kp>3).
\end{abstract}

Keywords: Mw 7.6, GPS TEC, Swarm Three Satellites, Ionosphere, Geomagnetic Storm.

\section{How to Cite:}

Rahman, Z. U. (2020). Possible Seismo Ionospheric Anomalies before the $2016 \mathrm{Mw} 7.6$ Chile Earthquake from GPS TEC, GIM TEC and Swarm Satellites. Natural \& Applied Sciences International Journal (NASIJ), 1(1), 11-20. https://doi.org/10.47264/idea.nasij/1.1.2

Publisher's Note:

IDEA PUBLISHERS (IDEA Journals Group) stands neutral regarding jurisdictional claims in the published maps and institutional affiliations.

\section{Copyright:}

(C) 2020 The Author(s), published by IDEA PUBLISHERS (IDEA Journals Group)

This is an Open Access article published under the Creative Commons Attribution-NonCommercial 4.0 International License (http://creativecommons.org/licenses/by-nc/4.0/) 


\section{Introduction}

The earthquake forecasting through ionospheric indices is ongoing debate among the scientific community and there are numerous reports on this topic using different ground and space based ionospheric measurement before and after the main shock (Ahmed et al., 2018; Shah \& Jin, 2015). However, the precursory nature of ionospheric signals before earthquake is still not proven. The earthquake induced ionospheric irregularities in the form of enhancement and depletion were reported from GPS based TEC over the epicenter (Shah and Jin, 2018; Shah et al., 2018). Similarly, ionospheric anomalies are also investigated from different satellite other than GNSS and similar variations are investigated from low frequency radio wave between the Earth and ionosphere over earthquake zones (Shah et al., 2019b; Tariq et al., 2019). However, earthquake induced perturbations should be distinguished from other sources triggering shortand long-term ionospheric anomalies. For example, there are several reports against earthquake ionospheric signature and correlated ionospheric anomalies with geomagnetic storms (Tariq et $a l ., 2019$ ) and opposed strongly that earthquake forecasting is complicated with current cluster of ground and space based measurements.

In previous reports, advancement in seismo ionospheric perturbation before the main shock has increased widely in the form of pre-earthquake signatures within seismogenic zone during earthquake preparation period. Synchronized and collocated ionospheric anomalies as bona fide pre-earthquake signatures have been registered in TEC, electron density and electron temperature from different satellite measurements (Shah et al., 2021; Timoçin et al., 2021). Similarly, reports are also available on the implementation of different statistical methods for delineating abnormal TEC values before the main shock. For example, (Shah et al., 2019a) statistically examined ionospheric abnormality within 10 days before the impending earthquake from the analysis in GPS and DEMETER values. Furthermore, they observed profound variations in ionospheric parameters (electron density and electron temperature) on earthquake latitudinal axis as compared to its conjugate axis. Mutual comparison of the ratio of electron density over earthquake latitude versus conjugate axis show abnormality trigger by the future main shock (Kiyani et al., 2020; Shah et al., 2020a; Shah et al., 2021). Similarly, a systematic magnetic field and associated electron density anomaly from Swarm satellites over the seismogenic zone of earthquake sequence in the absence of geomagnetic storm (Akhoondzadeh et al., 2018).

The two different descriptions of ionospheric anomalies before earthquake can be discuss on the basis of stress activated positive-hole (p-hole) model (Freund et al., 2009) or recombination of ions due to the emission of gases through lithosphere atmosphere ionosphere coupling model (Pulinets \& Ouzounov, 2011). Freund et al. (2009) proposed a model of the activation of pholes from earth crust during the earthquake preparation period, thus alter the electrical properties of surrounding rock and suddenly cause electromagnetic radiations and pulses. As p-holes reach the Earth surface, it ionizes the atmosphere around earthquake epicenter and further rise upward to lead cloud condensation. The upward motion of these p-holes creates instability in lithosphere atmosphere interface, specifically, cause variation in the mesosphere and in the lower ionosphere. On the other hand, Pulinets and Ouzounov (2011) proposed a model of rising up of gases including Radon and fluid particles from seismogenic zone during earthquake preparation period. The release of gases from seismogenic zone creates a chain of processes comprising of variation in earth surface temperature and humidity, atmospheric ionization by alpha particles, generation of aerosol size particle, anomalous electric 
conductivity and coupling of ionosphere by electrical and magnetic alterations. The coupling of lithosphere atmosphere ionosphere before large magnitude earthquake within seismogenic zone by numerical modelling.

All the above theories and models aim to propose an undisputable hypothesis of seismo ionosphere coupling however, no one provides an explicit definition of an ionosphere anomaly. In this paper, we analyzed temporal TEC before the 2016, $\mathrm{M}_{w}$ 7.6 Chile earthquake from GPS stations operating around the epicentre in (Dobrovolsky et al., 1979) region, and spatial TEC is investigated over epicentre from GIM. All these analyses manifested the mutual coupling of ionosphere and lithosphere trigger by the $2016 \mathrm{M}_{w}$ 7.6 Chile earthquake.

\section{Data and Method of Analysis}

In this paper, seismo ionospheric anomalies are investigated in the context of $2016, \mathbf{M}_{w} 7.6$, Chile earthquake (lat. $43.51^{\circ} \mathrm{S}$, long. $74.39^{\circ} \mathrm{W}$ ), which occurred as a result of thrusting in the south of Chile and triggered no tsunami (Figure 1). The focal depth was $30 \mathrm{~km}$ and it hits Chile on UT (14:22) in the Melinka region of southern Chile (LT=UT-5h), dubbed as Melinka earthquake. In Figure 1, one can see clearly the approach of ionospheric anomalies measurements within earthquake seismogenic zone from GPS. There are several reports on the association of different precursors with this earthquake from different ground and space measurements. More details about this earthquake are available on the website of USGS via the link (https://earthquake.usgs.gov/earthquakes).

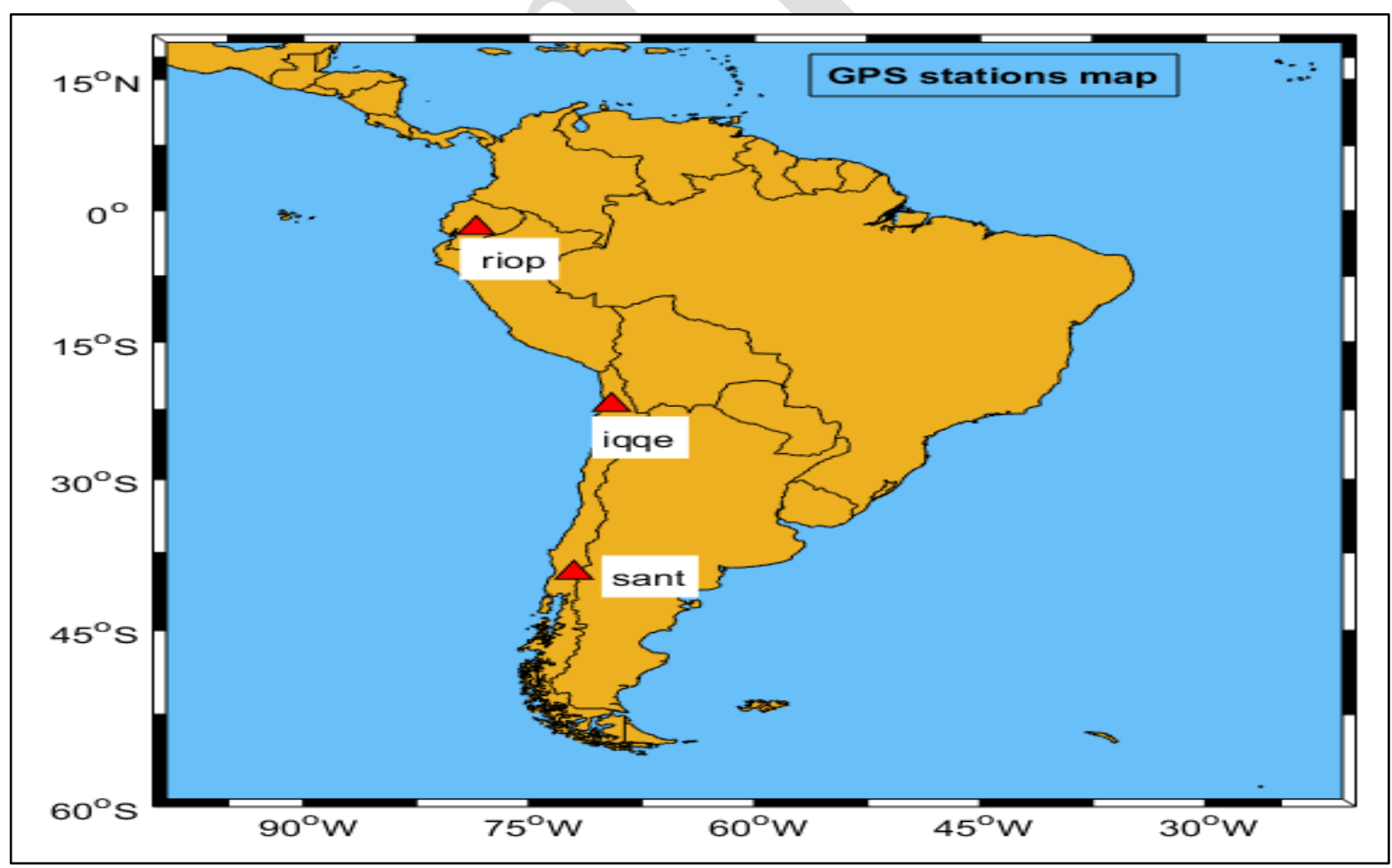

Figure 1: The geographical location of the December 25, 2016, $\mathrm{M}_{\mathrm{w}}$ 7.6 Chile earthquake in the middle of seismogenic zone estimated by Dobrovolsky formula. The epicenter is denoted by red fill star and it hits the region on UT $=14: 22$. The IGS GPS stations are showed by black triangle.

In order to confirm the response of different ionospheric indices before and after the earthquakes, it is necessary to check the geomagnetic storm conditions to distinguish the 
seismo ionospheric anomalies from the storm. In this study, the geomagnetic storms indices during the month of December 2016 are showed from Dst, AE, Ap and F10.7 before and after the main shock (Figure 2). The geomagnetic storm indices are obtained from OMNI web through the web page (https://omniweb.gsfc.nasa.gov/form/dx1.html). We analyzed TEC from GNSS stations within the seismogenic zone of $\mathrm{M}_{w}$ 7.6 Chile earthquake, where the seismogenic zone is determined by Dobrovolsky et al. (1979):

$$
R=10^{0.43 M}
$$

where $M$ is the magnitude and $R$ is the radius of the earthquake affected zone. Furthermore, Eq. (1) indicates that radius of seismogenic zone is dependent on the earthquake magnitude; e.g., high magnitude earthquakes may have large preparation zones and vice versa (Shah et al., 2019b).

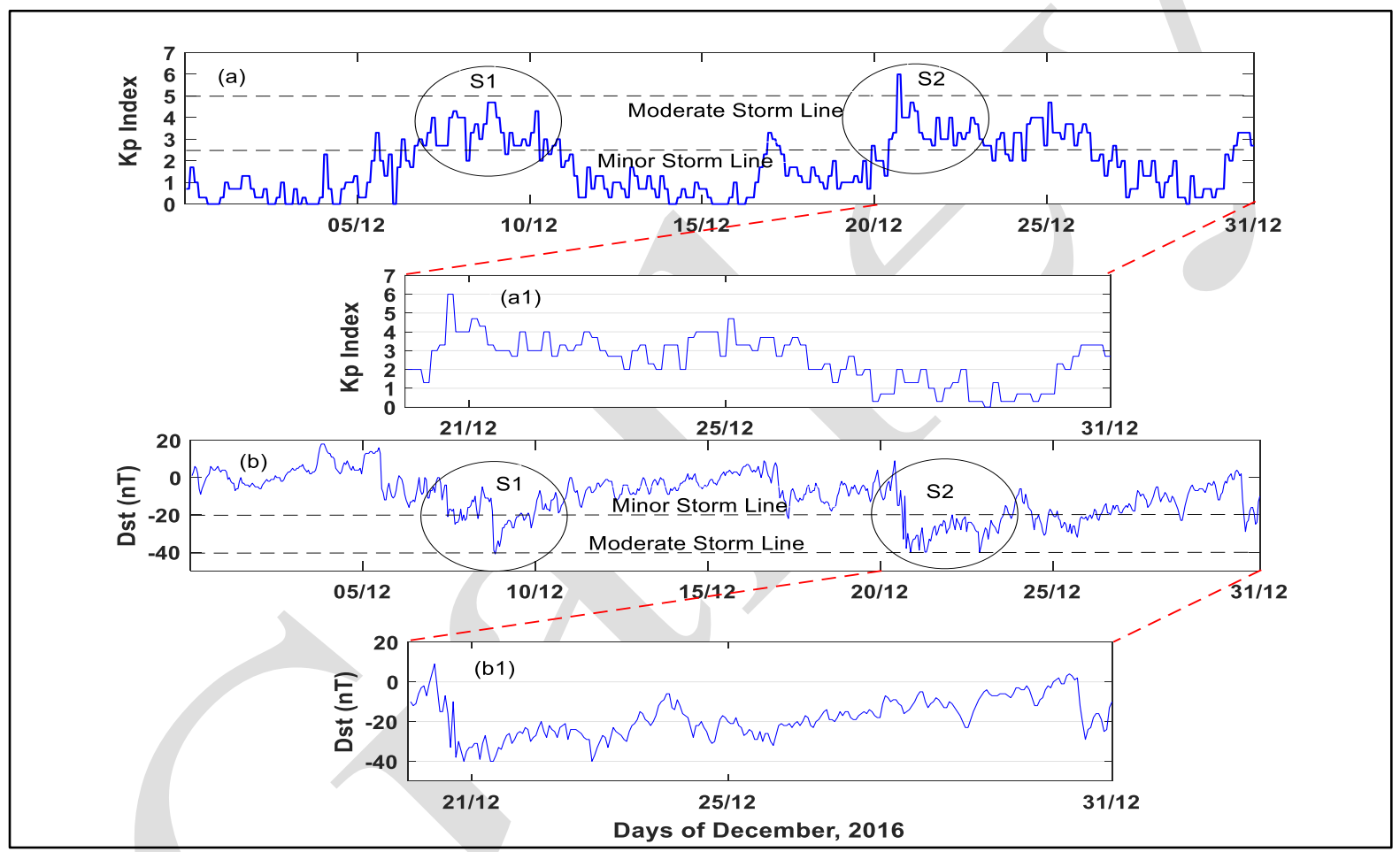

Figure 2: Solar and geomagnetic storm indices for the month of December 2016 before and after $\mathbf{M}_{w}$ 7.6, earthquake.

The TEC anomalies from three GNSS stations (Iqqe, Antc and Sant) are investigated within the critical region for the month of December 2016 before and after the main shock. The TEC values are retrieved during the local time (UT-5h) of Chile and bounded by confidence intervals of median and Inter Quartile Range (IQR), as below:

$$
\begin{aligned}
& X_{\text {upper Bound }}=\mu+\mathrm{IQR} \\
& \mathrm{X}_{\text {lower Bound }}=\mu-\mathrm{IQR} .
\end{aligned}
$$

The confidence bounds for the observed day are obtained from the median and IQR of 10 days before/after the day under study. Similarly, in situ temporal TEC from GIM is also analyzed for the respective days of December 2016 to provide evidences to TEC perturbations. The GIM TEC is also bounded by the same method of median and IQR. 
In this paper, we used TEC and electron density from European Space Agency (ESA), Swarm satellite to provide stringent proof of seismo ionospheric anomalies. Swarm three satellites mission is successfully launched on 22/11/2013 by ESA for the monitoring of different ionospheric parameters with high precision never achieved before. Some of the dedicated missions achieved so far from Swarm are: lithospheric high resolution magnetic map up to 250 $\mathrm{km}$ (Akhoondzadeh et al., 2018), earthquake related ionospheric anomalies detection and effects of oceanic tides on geomagnetic field (Akhoondzadeh et al., 2018). The Swarm mission has three identical satellites in the constellation and all satellites are still in orbit. In the month of August 2016, two satellites (Alpha and Charlie) of Swarm's mission are in lower orbit of about $450 \mathrm{~km}$ above sea level and the third satellite (Bravo) of this constellation has relatively high orbit of about $512 \mathrm{~km}$ above sea level. This particular orbital configuration allows Swarm to achieve several scientific objectives, specifically, the super alignment in Alpha and Charlie can easily measure the field aligned current in the radial direction. Similarly, the different orbital heights of Swarm (Alpha and Charlie) and Bravo allow monitoring the different ionospheric indices at different altitude. The orbital configuration is not fixed as Alpha and Charlie satellites lapse behind than Bravo along the years, e.g., initially Bravo satellite was close to Alpha and Charlie, now it has $90^{\circ}$ difference. This allows us to monitor ionosphere over the seismogenic zone and to distinguish seismic anomalies from geomagnetic with high precision. The day and night-time TEC from Swarm three satellites are further bounded by the confidence bounds of median and associated IQR to quantify the variation before $\mathbf{M}_{w}$ 7.6. The confidence bounds of TEC values are calculated from the median and IQR of the total TEC values in the month of December 2016.

\section{Results}

In this study, the seismo ionospheric anomalies before the $\mathrm{M}_{w} 7.6$, Chile earthquake are studied in multi-ionosphere indices from TEC and Swarm in the month of December 2016 during the seismic preparation period. The TEC from GNSS stations and GIM is obtained during the local time (UT-5h) for Chile earthquake. The TEC from GNSS stations within Dobrovolsky et al. (1979) region and GIM over the epicenter show significant ionospheric anomalies beyond the confidence intervals prior to main shock. We observed significant ionospheric perturbations in TEC from GNSS stations around epicenter within the seismogenic zone for 10 days before the main shock (Figure 3). However, the storm in Kp is significantly active with an intensity of $\mathrm{Kp}>3$ on the same day as ionospheric variation. The monitoring of solar activity and geomagnetic storms is very important in earthquake precursory study to distinguish the earthquake induced anomaly from geomagnetic storm. There are several reports about the association of TEC anomalies with geomagnetic storms (e.g., Shah et al., 2020a; Shah et al., 2020b; Shah et al., 2020c; Tariq et al., 2020). We observed ionospheric anomaly at Iqqe and Antc stations on December 21, 2016 (4 days before main shock) against Kp>3 geomagnetic storm and anomalous TEC value at Sant station occurred on December 18, 2016 (Figure 3c). Similarly, the GIM TEC anomaly correlated with GPS stations (Iqqe and Antc) on December 21, 2016, where an enhancement of more than 10 TECU occurs on the suspected day. On the other hand, TEC anomalies from the three GNSS stations were also investigated for a geomagnetic storm in the month of May 2016 to distinguish seismic anomalies. However, we observed no clear abnormalities associated to earthquake and it is possibly related to geomagnetic storm. It points that the observed anomaly on December 21, 2016 is due to active storm activity. The dissemination of seismo ionospheric anomalies in active storm days need more evidence. 
Temporal TEC anomaly on December 21, 2016 is further analyzed spatially over epicenter to provide reasonable evidence to possible seismic perturbations associated with earthquake. The bi-hourly spatial TEC maps showed dense electron clouds over epicenter during LT (12:0014:00) and immediately lasts after LT=14:00 (Figure 4). These dense electron clouds over epicenter in the Chile region during daytime is due to future earthquake because this day already shows abnormal TEC values beyond confidence intervals in the analysis of GNSS stations. The TEC values in temporal analysis overlapped the upper confidence bound for $4 \mathrm{~h}$, which occurred in spatial TEC also. Hence, these temporal and spatial TEC anomalies are suspected due to earthquake and may be attributed to geomagnetic storm during this time period $(\mathrm{Kp}>3)$.

To validate the geomagnetic anomaly prior to $\mathrm{M}_{w} 7.6$ earthquake, temporal TEC in the day and night-time from Swarm three satellites around the epicenter within the Dobrovolsky et al. (1979) region for the month of December 2016 is studied (Figure 5). It can be noted that temporal TEC is bounded by the confidence intervals of median and associated IQR for the designation of storm time anomalous value. These anomalies also collocate with GPS TEC and GIM TEC for storm time abnormal ionospheric variations, as geomagnetic storm active before the main shock with $\mathrm{Kp}>3$.

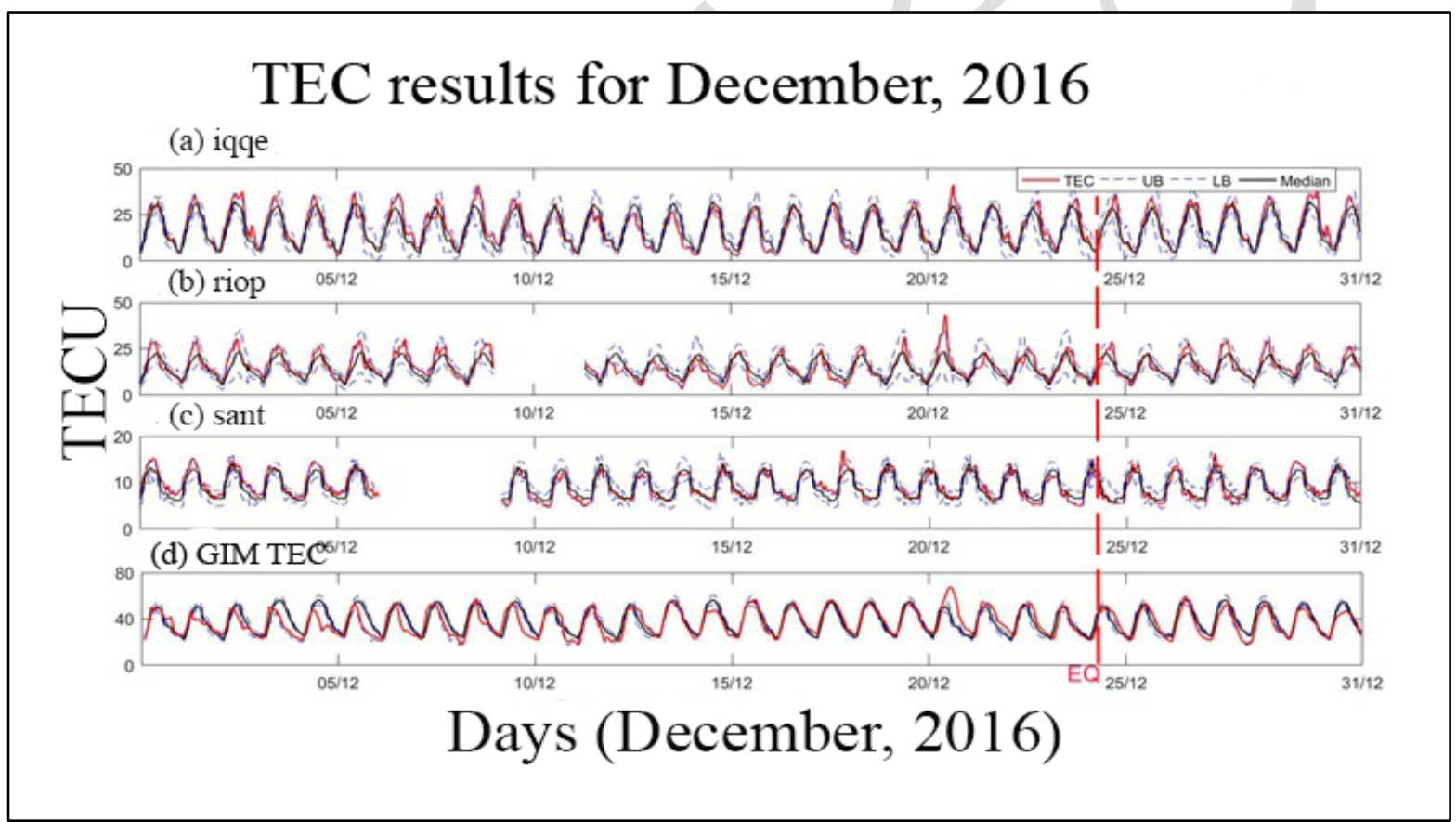

Figure 3: TEC measurements from (a) Iqqe, (b) Antc, (c) Sant, and (d) GIM within the seismogenic zone of $M_{w} 7.6$ for the month of December 2016 before and after the earthquake. The blue dotted lines are representation of confidence bounds and red dashed line for earthquake. Similarly, the influence of a geomagnetic storm in May 2016 was also checked in TEC for all studied stations. We observed no pronounced perturbations particularly to this storm, which support our hypothesis of seismo ionosphere disturbance on December 21, 2016 prior to Chile earthquake.

\section{Discussion}

In this paper, multi-ionosphere parameters are analyzed in the context of $\mathrm{M}_{w}$ 7.6 Chile earthquake and an active geomagnetic storm ( $\mathrm{Kp}>3)$ from GPS, GIMs and Swarm three satellites in December 2016 over the epicenter. Evidence reports abnormal enhancement in 
temporal TEC in ionosphere over the epicenter due to geomagnetic storm (Figure 3-5). The earthquake anomalies are not evident before and after the earthquake. In addition to temporal TEC, spatial TEC also show abnormal values over epicenter due to active geomagnetic storm $(\mathrm{Kp}>3)$. The three Swarm satellites provide sufficient evidence to justify storm time ionospheric coupling, as storm is clear in one index $(\mathrm{Kp})$ of all geomagnetic activity indices. Moreover, there is a lack of seismic abnormality in lower and upper ionosphere (Figure 3-5).

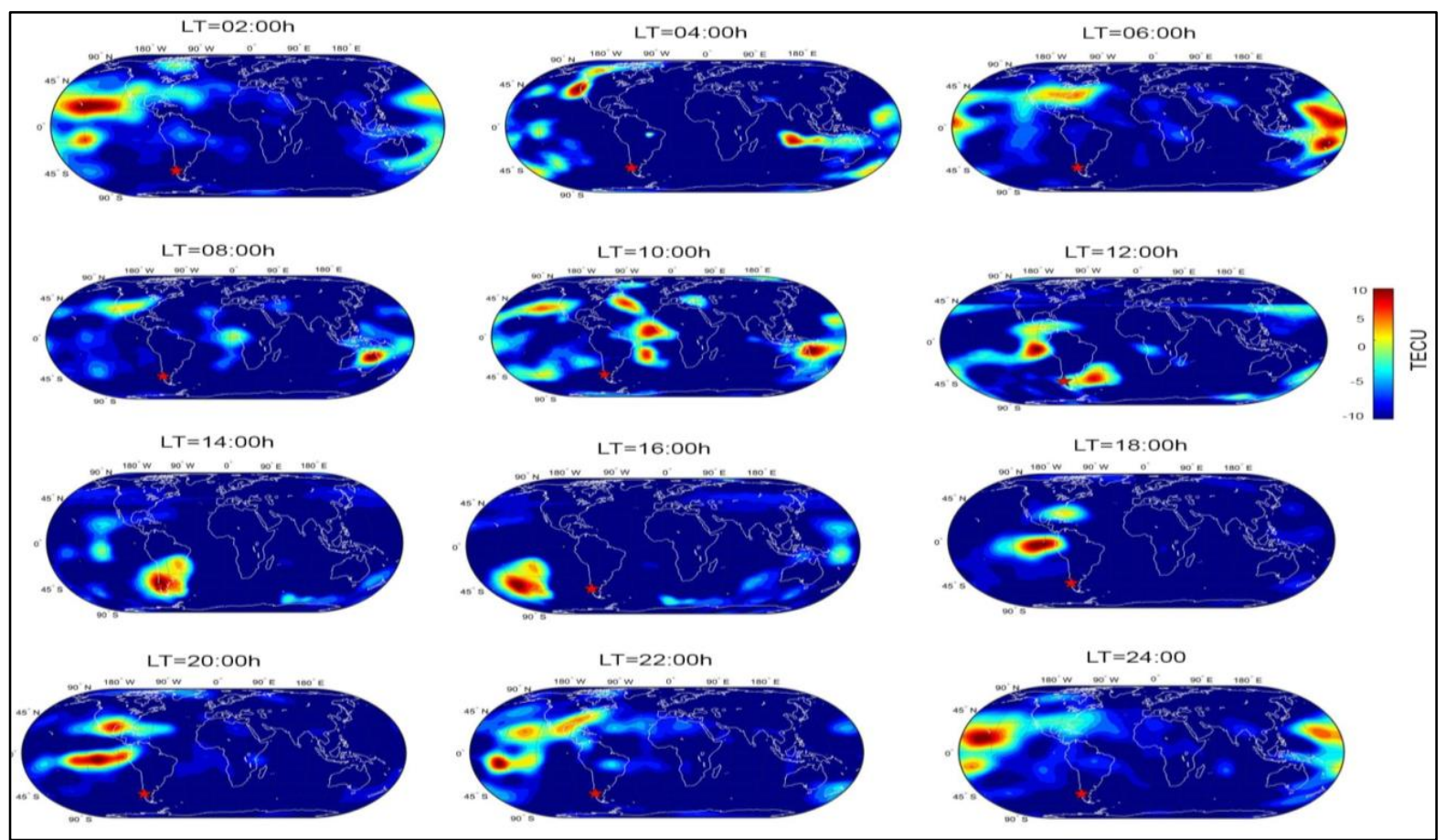

Figure 4: Differential spatial TEC maps from GIM on December 21, 2016 before $\mathrm{M}_{\mathrm{w}}$ 7.6, Chile earthquake. The red filled star is for earthquake epicenter and time is represented as local time.

The purpose of this paper of deriving ionospheric anomalies from different satellites is to draw a concrete conclusion to the mechanism of seismo ionospheric anomalies for revealing the features originated from seismic activities. However, the link between lithosphere and ionosphere can be explained in the light of previous reports to further clear the source point of these anomalies. For example, (Oyama et al., 2011) distinguished intrinsic seismic anomalies in the form of reduction of ionospheric indices of U.S satellite DE-2 in the coastal region of Chile. On the other hand, Shah et al. (2019) reported anomalous electron clouds on earthquake latitude than the average value of southern hemisphere in the analysis of multi-satellite measurement (GPS TEC and DEMETER). Similarly, they also compared electron clouds on the earthquake latitude and its geographic conjugate axis, where a definite ionospheric variation occurred before the earthquake within seismic preparation period.

Seismo ionospheric anomalies occurred due to the increase and decrease in atmospheric conductivity over the seismogenic zone by abnormal emission and reduction of Radon emanation (Pulinets and Ouzounov, 2011). In this study, the enhancement in ionosphere in multi-satellite analysis can be explained by an abnormal rise in atmospheric conductivity in Chilean sector. The Figure 10 in Pulinets and Ouzounov (2011) can clearly show the concept of lithospheric ionospheric coupling through the global circuit for increased air conductivity within earthquake breeding zone, which completely matched with the positive enhancement in this study for $M_{w}$ 7.6, Chile earthquake. The theory of Pulinets and Ouzounov, (2011) for 
triggering positive ionospheric anomalies through lithosphere ionosphere coupling was modeled. They reported perturbation in lower bottom of ionosphere before earthquake within the seismogenic zone due to thermal heating from epicentral region. However, the propagation of ionospheric anomaly before earthquake through the lower atmosphere can be explained by the concept of positive holes generation in earthquake prone region. Since, the propagation of pre-seismic anomalies and their travel path from the lithosphere to ionosphere via atmosphere is still debatable.

Freund et al. (2009) observed that the production of positive holes within earthquake prone regions and associated fault lineament as a result of squeezed rock can alter the electric potential of the atmosphere. He showed that earthquake generates positive holes within the preparation period before the main shock. Furthermore, Freund et al. (2009) confirmed in a laboratory that further influx of positive holes from earth surface to atmosphere must lead to the high electric field. Finally, the values of these electric fields reach so high due to more influx to accelerate the available free electrons, which are already present in the air due to radioactive decays, to further ionize neutral gas particles due to sufficient kinetic energies. Eventually, it is triggering process of corona discharges, which then produce small light glow and abnormal free electron.

TEC around epicenter from GNSS stations and over epicenter from GIM completely correlated within 10 days before the main shock over the seismogenic zone (Figure 3 and Figure 4). This shows that the theory of positive holes generation at ground and its propagation to ionosphere can be acceptable in the light of Freund et al. (2009). They linked the abnormality in the ionosphere acquired by vertical profiles as a result of positive holes emanation from earth crust and its complex reaction at ground-atmosphere interface.

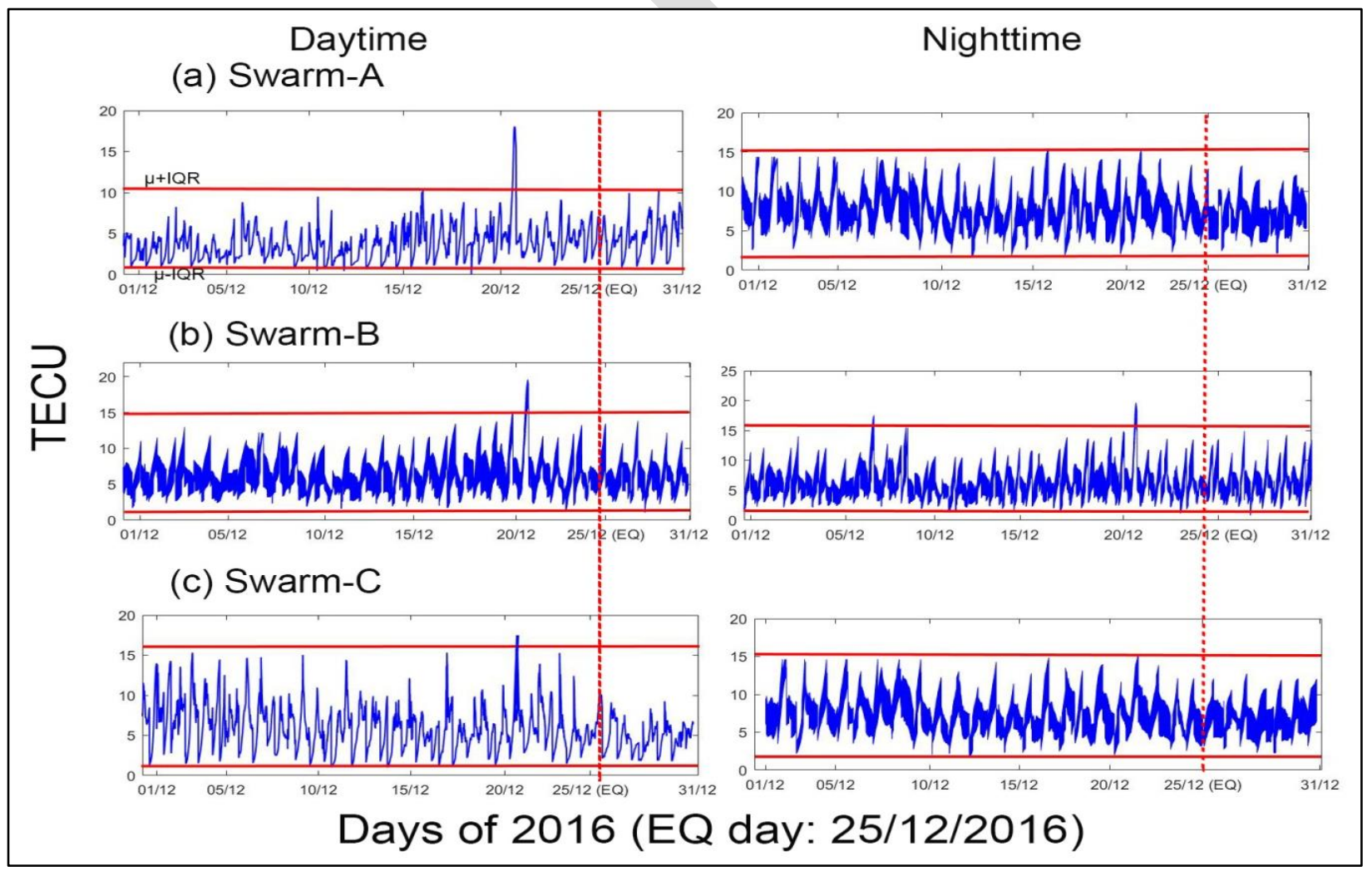

Figure 5: Swarm A, B and C satellite data for analysis in the context of Chile earthquake. 


\section{Conclusion}

In this paper, ionospheric TEC perturbations are analyzed from GPS and Swarm satellite for a case study of active geomagnetic storm and earthquake during December 2016 in Chile region. Temporal TEC vary about more than 10 TECU beyond upper bound on December 21, 2016 (4 days) before the main shock during the investigation of GNSS stations and in situ GIM measurements over epicenter. But the active storm condition (Kp>3) summons up to correlate these as geomagnetic storm anomalies. Similarly, spatially significant TEC clouds are found over epicenter on the suspected day (i.e., December 21, 2016) during LT=12:00h-14:00h within the seismogenic zone. Temporal and spatial TEC, electron density and electron temperature from Swarm three satellites also confirm suspected ionospheric anomaly on December 21, 2016 (4 days) before main shock during investigation of integrated seismic precursor sequence related to $\mathbf{M}_{w}$ 7.6, Chile earthquake. All these analyses confirm that earthquake associated ionospheric anomalies can be possibly related in quiet storm conditions. The correlation of earthquake and ionosphere in the form of lithosphere ionosphere coupling from multiple ionospheric measurements need more attention and analyses.

\section{Acknowledgement}

We are thankful to IGS community for providing GPS TEC and GIM TEC data and OMNI web for Geomagnetic storm indices. The authors are also thankful to ESA for providing Swarm satellites data.

\section{References}

Ahmed, J., Shah, M., Zafar, W. A., Amin, M. A. and Iqbal, T. (2018). Seismoionospheric anomalies associated with earthquakes from the analysis of the ionosonde data. Journal of Atmospheric and Solar-Terrestrial Physics, 179, 450-458. https://doi.org/10.1007/s0002 4-019-02149-9

Akhoondzadeh, M., Parrot, M., \& Saradjian, M. R. (2010) Electron and ion density variations before strong earthquakes $(M>6.0)$ using DEMETER and GPS data. Nat Hazards Earth Syst Sci 10(1):7-18. https://doi.org/10.5194/nhess-10-7-2010

Dobrovolsky, I. P., Zubkov, S. I. and Miachkin, V. I. (1979). Estimation of the size of earthquake preparation zones. Pure and Applied Geophysics, 117(5), 1025-1044. https://doi.org/10.1007/BF00876083

Freund, F. T., Kulahci, I. G., Cyr, G., Ling, J., Winnick, M., Tregloan-Reed, J., \& Freund, M. M. (2009). Air ionization at rock surfaces and pre-earthquake signals. Journal of Atmospheric and Solar-Terrestrial Physics, 71(17-18): 1824-1834. https://doi.org/10.1016/j.jastp.2009.07.013

Kiyani, A., Shah, M., Ahmed, A., Shah, H. H., Hameed, S., Adil, M. A., \& Naqvi, N. A. (2020). Seismo ionospheric anomalies possibly associated with the $2018 \mathrm{Mw} 8.2 \mathrm{Fiji}$ earthquake detected with GNSS TEC. Journal of Geodynamics, 140, 101782. https://doi.org/10.1093/gji/ggv376

Pulinets, S., \& Ouzounov, D. (2011). Lithosphere-Atmosphere-Ionosphere Coupling (LAIC) model - An unified concept for earthquake precursors validation. Journal of Asian Earth Sciences, 41(4-5), 371-382. https://doi.org/10.1016/j.jseaes.2010.03.005 
Shah, M., \& Jin, S. (2015). Statistical characteristics of seismo-ionospheric GPS TEC disturbances prior to global $\mathrm{Mw} \geq 5.0$ earthquakes (1998-2014). Journal of Geodynamics, 92, 42-49. https://doi.org/10.1016/j.jog.2015.10.002

Shah, M. \& Jin, S. (2018). Pre-seismic ionospheric anomalies of the $2013 \mathrm{Mw}=7.7$ Pakistan earthquake from GPS and COSMIC observations. Geodesy and Geodynamics, 9(5): 378-387. https://doi.org/10.1016/j.geog.2017.11.008

Shah, M., Khan, M., Ullah, H., \& Ali, S. (2018). Thermal anomalies prior to the 2015 Gurkha (Nepal) earthquake from MODIS Land Surface Temperature and Outgoing Longwave Radiations. Geodynamics \& Tectonophysics, 9(1): 123-138. https://doi.org/10.5800/GT-2018-9-1-0341

Shah, M., Tariq, M.A., Ahmad, J., Naqvi, N.A., Jin, S., (2019a). Seismo ionospheric anomalies before the 2007 M7.7 Chile earthquake from GPS TEC and DEMETER. J. Geodyn. 127, 42-51. https://doi.org/10.1016/j.jog.2019.05.004.

Shah, M., Tariq, M.A., Naqvi, N.A., (2019b). Atmospheric anomalies associated with Mw>6.0 earthquakes in Pakistan and Iran during 2010-2017. J. Atmos. Sol.-Terr. Phys. 191, 105056 https://doi.org/10.1016/j.asr.2017.07.007

Shah, M., Aibar, A. C., Tariq, M. A., Ahmed, J., Ahmed, A., (2020a). Possible ionosphere and atmosphere precursory analysis related to $\mathrm{Mw}>6.0$ earthquakes in Japan. Remote Sens Environ. https://doi.org/10.1016/j.rse.2019.111620

Shah, M., Ahmed, A., Ehsan, M., Khan, M., Tariq, M. A., Calabia, A., \& Rahman, Z., (2020b). Total electron content anomalies associated with earthquakes occurred during 19982019. Acta Astronaut. https://doi.org/10.1016/j.actaa stro.2020.06.005

Shah, M., Inyurt, S., Ehsan, M., Ahmed, A., Shakir, M., Saleem, U., Iqbal. M. S., (2020c). Seismo ionospheric anomalies in Turkey associated with $\mathrm{Mw} \geq 6.0$ earthquakes detected by GPS stations and GIM TEC. Adv Space Res 65(11): 2540-2550. https://doi.org/10.1016/j.asr.2020.03.005

Shah, M., Qureshi, R. U., Khan, N. G., Ehsan, M. and Yan, J., (2021). Artificial Neural Network based thermal anomalies associated with earthquakes in Pakistan from MODIS LST. Journal of Atmospheric and Solar-Terrestrial Physics, 215, 105568. https://doi.org/10.1016/j.jastp.2021.105568

Tariq, M.A., Shah, M., Inyurt, S., Shah, M.A. and Liu, L. (2020). Comparison of TEC from IRI-2016 and GPS during the low solar activity over Turkey. Astrophysics and Space Science, 365(11), 179. https://doi.org/10.1007/s10509-020-03894-3

Tariq, M. A., Shah, M., Ulukavak, M., \& Iqbal, T. (2019). Comparison of TEC from GPS and IRI-2016 model over different regions of Pakistan during 2015-2017. Advances in Space Research, 64(3): 707-718. https://doi.org/10.1016/j.asr.2019.05.019

Timocin, E., Temucin, H., Inyurt, S., Shah, M., \& Jamjareegulgarn, P. (2021). Assessment of improvement of the IRI model for foF2 variability over three latitudes in different hemispheres during low and high solar activities. Acta Astronautica, 180, 305-316. https://doi.org/10.1016/j.actaastro.2020.12.042 